\title{
Mycoflora of sawn timbers in Benin City
}

\author{
J. A. OKHUOYA, S. O. ITAMAN \\ Department of Botany, University of Benin, \\ P.M.B. 1154, Benin City, Nigeria
}

Okhuoya J.A., Itaman S.O.: Mycoflora of sawn timbers in Benin City. Acta Mycol. $23(2)$ : 89-95, 1987 (1990).

In a fungal survey of sawn timbers in scattared localities in Benin City, fungal species isolated were mainly members of Hyphomycetes, with few Ascomycetes and Basidiomycetes. Cellulolytic abilities of isolates were determined and fuond to be highest in a basidiomycete, Pleurotus ostreatus. The high incidence of these isolates was traced to the poor ventillation in the shades where the timbers are sold and the high moisture content of timber before display for sale.

\section{INTRODUCTION}

Timber, a chief product of the forest, is a universally useful raw material and a foreign exchange earner for Nigeria (Panshin and Carl 1964; Kollman et al 1975; Titmus 1965; Von Wendorff and Okigbo 1963; Adeyoju 1975). Since man learnt to use timber for various purposes, it has been a target of fungal attack resulting in wood decay. However there has been an increased interest in preventing unnecessary wastage of timber by fungal attack through preservation and maintenance of wooden structures (Ramsbottom 1937; Boyce and Hepting 1943; Cartwright and Findlay 1958; Line and Cruickshank 1979).

In Benin City, timber shades exist in different parts of the city without proper precautionary measure to prevent fungal attack on them. This has the potential of making these timbers vulnerable to fungal deterioration. This study was therefore carried out to survey the different fungi associated with timber in these shades. 
MATERIALS AND METHOD

Timber Sampling

\section{Microfungi}

Timber located in five stations at Uselu, Ugbowo, Okhoro, Ogida and New Benin were sampled. Samples of the infected wood from each location were taken at weekly intervals from November 1983 to January 1984, kept in sterile polythene bags and taken to the laboratory for examination. The temperature and relative humidity of each location was recorded during each sampling period. The method of Line and Cruickshank (1979) was modified and used to isolate the fungi. Thin wood sawings were cut with a sterilised scalpel, and placed on sterile potato dextrose agar (PDA) which were incubated at room temperature $\left(28 \pm 2{ }^{\circ} \mathrm{C}\right)$. At the end of incubation, 5-8 days, isolates were examined under the microscope and identified at least to the generic level.

\section{Macrofungi}

The fruiting bodies of the macrofungi found on timber in the different localities were carefully excised, put in a sterile polythene bag and sent to the laboratory for identification.

Assessment of cellulase activity:

The methods of Rautela and Lowling (1966) as later modified by Tansey (1971) was used. Vertical columns $(3-4 \mathrm{~cm})$ of the medium were prepared in sterile test tubes. These columns were inoculated with discs of fungal mycelium, from a 7-day old culture, and were then incubated at room temperature. Depths of the medium cleared in the tubes were measured at weekly intervals. The average depths for three replicates were taken as a measure od cellulose activity.

Weight loss determination:

Three samples of timber $(10 \times 5 \times 5 \mathrm{~mm})$ were made from each sampling site, and sterilised in the autoclave at $103.4 \mathrm{KN} / \mathrm{M}^{2}$ for 15 minutes. They were then oven dried at $100^{\circ} \mathrm{C}$ in sterile containers for $18 \mathrm{hrs}$. and their weights determined. The test timber pieces were then placed on PDA plates (3 per plate, in triplicates), previously inoculated with each of the fungal isolates which have been found to be positive in cellulose test.

The cultures were then incubated at room temperature for two months. Sterile distilled water was occasionally added to the medium to prevent drying. At the end of the incubation the blocks were removed from the petri dishes and the superficial fungus mycelium was scraped off the block carefully, avoiding to the blocks. 
The blocks were then oven dried and reweighed. The losses in dry weight of the blocks were estimated by the difference between the initial dry weight and the final dry weight after inoculation.

\section{RESULTS}

Both micro- and macrofungi were isolated from the different sites of timber sampling (Tables 1 and 2). Out of the frequently occurring fungi isolated from the localities, Mucor racemosus, M. mucedo, Rhizopus stolonifer did not clear cellulose within a three week period (Table 3 ). The macrofungal isolates had higher records of cellulose clearing and weight lossen than the microfungi. P. ostreatus had the highest weight loss $(14.9 \%)$.

The temperature and relative humidity in all the locations were relatively constant $28-30{ }^{\circ} \mathrm{C}$ and $65-70 \%$ respectively.

\section{DISCUSSION}

From the results of this study it appears that fungal deterioration of timber in Benin City is caused mainly by members of the Hyphomycetes and Hymenomycetes, with few Ascomycetes. P. ostreatus and $S$. lacrymans were the most active wood degraders with $14.9 \%$ and $14.0 \%$ weight losses respectively. Similar observation has been made by Line and Cruickshank (1979) who found $P$. ostreatus to have the greatest cellulose activity. S. lacrymans was found to be more widespread in the city $(15 / 15)$ than P. ostreatus $(14 / 15)$.

Although most Hyphomycetes were not as active apart from Trichoderma $(9.0 \%$ loss $)$, they were very common in all the location sampled, e.g. Aspergillus niger (15/15), Penicillia 15/15, Trichoderma 15/15. The few Ascomycetes isolated (Chaetomium 12/15, Daldinia 14/15, Xylaria 13/15), were effective wood degraders with percentage weight loss 13.0, 13.8, 6.3 respectively.

The degradability of these isolates appear to follow the taxonomic disposition of the fungi in the order, Basidiomycetes; Ascomycetes and Phycomycetes. Similar reports have been made by Thornton (1979) and Line and Cruickshank (1979). Some species, namely M. racemosus, M. mucedo and $R$. stolonifer (Table 3), shoved the ability to degrade wood but failed to produce cellulase in culture on cellulose agar. This apparent anomally has also been observed by other workers, Line and Cruickshank (1979) and Ni1son (1974) who isolated a wide variety of wood-attacking microfungi that showed this feature.

One of the possible reasons according to Wilson (1974) is that the carbon in the cellulose agar medium is in soluble from and as a result there was to tendency for production of cellulase by the fungi. In general terms, the high values for tempt and low $\mathrm{RH}$ during the dry season months are not favourable 


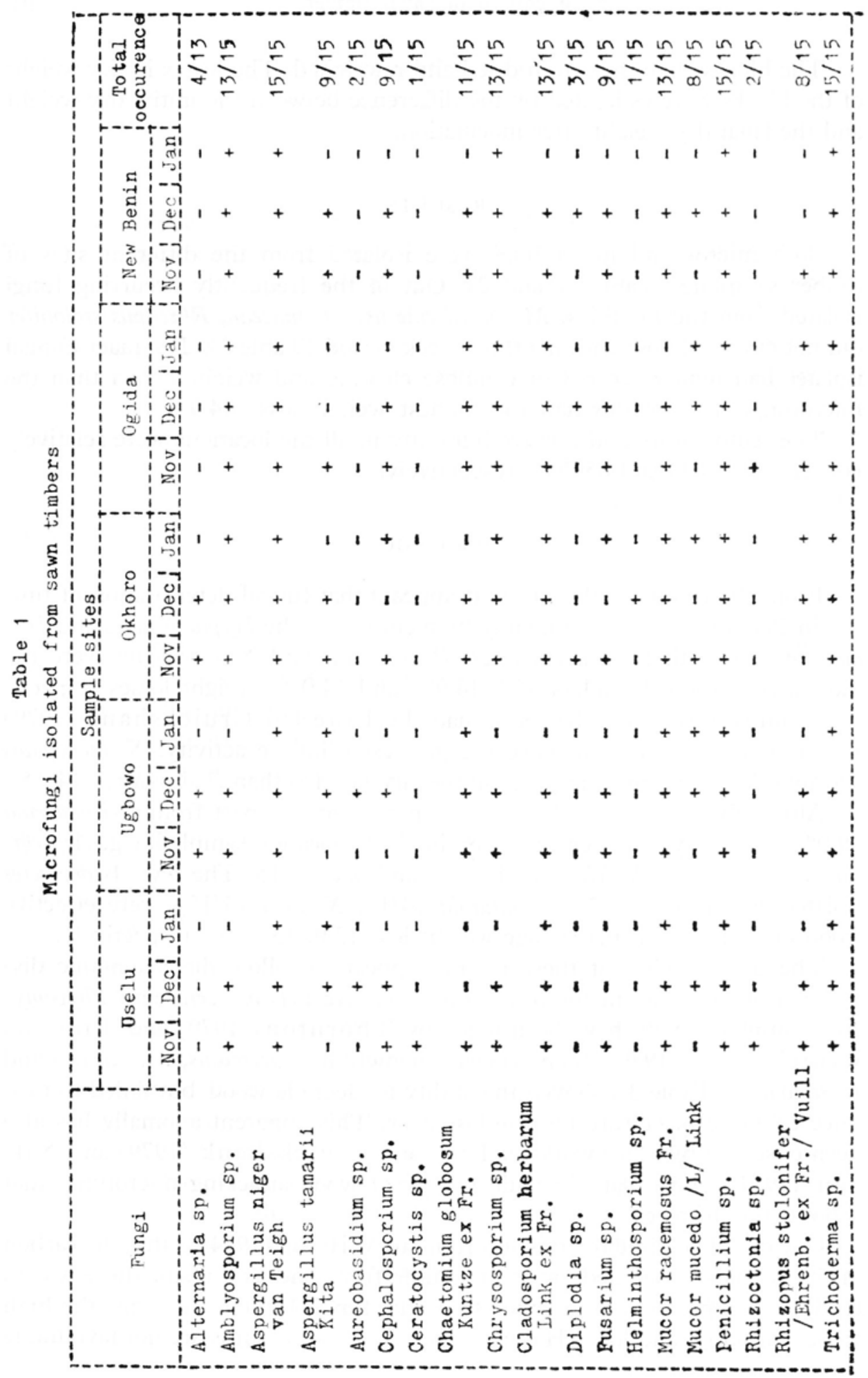




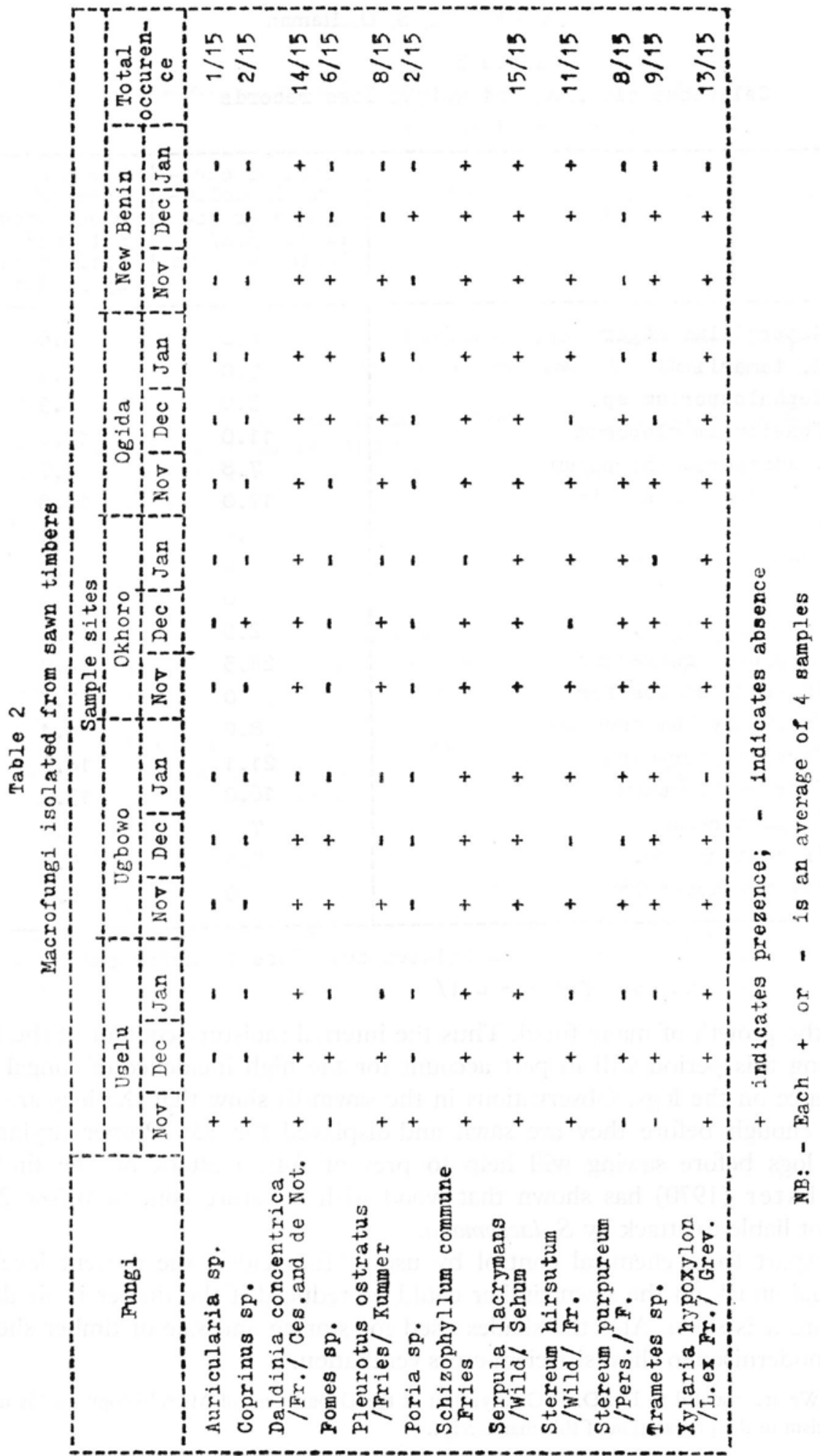


Table 3

Cellulose clearing and weight loss records of selected isolates

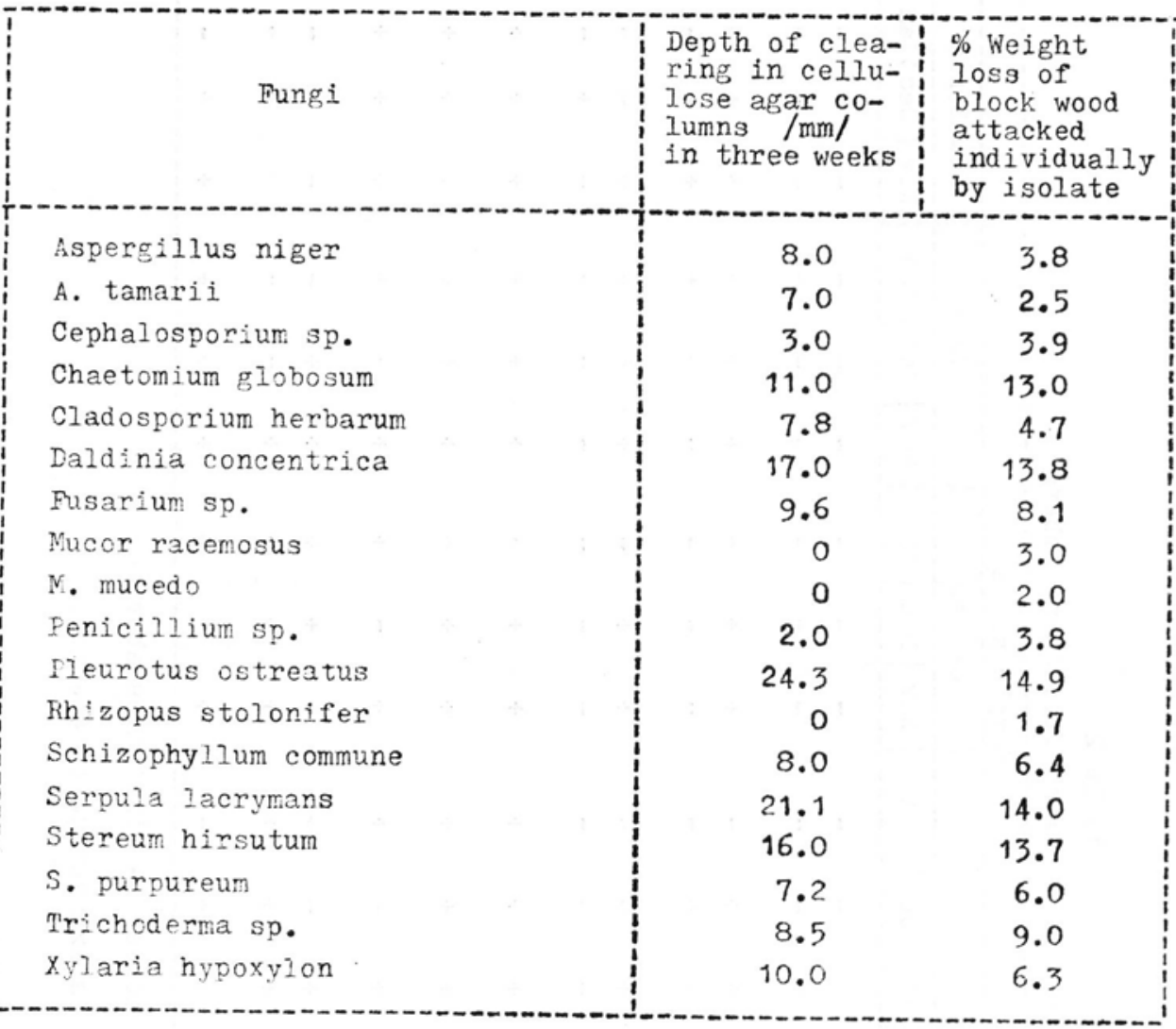

Positive correlation between cellulose clearing and weight Ioss /at $\mathrm{P}=0.1 /$

for the growth of many fungi. Thus the internal moisture content of the logs during this period will in part account for the high incidence of fungal occurence on the logs. Observations in the sawmills show that the logs are not dry enough before they are sawn and displayed for sale. Proper drying of the logs before sawing will help to prevent fungal attack on the timber. Webster (1970) has shown that wood with moisture content below $20 \%$ is not liable to attack by $S$. lacrymana.

Apart from chemical control by use of fungicides, the present level of fungal attack on the sawn timber could be reduced if the timber is air dried before it is sawn. Also the shades used for storing and sale of timber should be modernised to allow sifficient cross ventilation.

We are grateful to Dr. D. K.G. Ayanru of the Department of Microbiology for his useful criticism in the preparation of this manuscript. 


\section{Mikoflora drewna budulcowego w Benin City (Nigeria)}

\section{Streszczenie}

Autor wyizolował różne Hyphomycetes, kilka Ascomycetes i Basidiomycetes. Z grzybów tych najwyższą zdolnością celulolityczną odznaczał się Pleurotus ostreatus.

\section{REFERENCES}

Adeyoju S.K., 1975, Forest and the Nigerian Enconomy. Ibadan University Press. 308 p. Boyce J.S. and Hepting G.H., 1943, Decay of wood in aircrafts. U.S. Dept. Agric. For. Patt. Spec. Re. No. 12: 4

Bravery A.F., 1968, Microbiological breakdown of cellulose in the pressence of alternative carbon source. J. Sci. Fd. Agr. 19: 133-135.

Cartwright K.S.G. and Findlay W.P.K., 1958, Decay of Timber and its Prevention, 2nd edition, H.M.S.O. London 332 P.

Kollman F.F.P., Kuenzi E.W. and Stamm A.J., 1975, Principles of Wood Science and Technology. Springer-Verlag Berlin Heidelberg, New York 708 p.

Line M.A. and Cruickshank R.H., 1979, Softrot fungi from Copperchrome-arsenic treated hardwood Transmission Poles in Tasmania. Int. Bioderior Bull. 15: 113-118.

Nils on T., 1974, The degradation of cellulose and the production of cellulose, xynalase, mannanase, and amylase by wood attacking microfungi. Studia Forestalia Suecina 114: 59-61.

Panshin A.J. and Carlz, 1964, Textbook of Wood Technology 3rd edition. McGraw-Hill Book Company. N.Y. 795 p

Ramsbotto m J., 1937, Dryrot in ships. Essex Naturalist 25: 231-261.

Rantela G.S. and Cowhing E.B., 1966, Simple cultural test for relative cellulolytic activity of fungi. Appl. Mikrobiol. 14: 892-898.

Tansey M.R., 1971, Agar diffusion assay of cellulolytic ability of thermophilic fungi. Arch. Mikrobiol. 77: 1-11.

Thornton J.D., 1979, Evaluation of a new laboratory decay technique using Serpula lacrymans. Int. Biodeterior Bull. 15: 45-48.

Von Wendorft G. and Okigbo L., 1963, Some Nigerian Woods. Federal Ministry of Information Lagos, Nigeria 61 p.

Webster J., 1970, Introduction to Fungi. Cambridge University Press, 424 p. 